\title{
Efisiensi Pengelolaan Zakat dalam Tinjauan Fatwa Majelis Ulama Indonesia
}

\author{
Novendi Arkham Mubtadi, ${ }^{\bowtie}$ Dwi Vera Usmadyani, Farah Annisa’
}

\author{
Institut Agama Islam Negeri Pekalongan \\ novendi.arkham.mubtadi@iainpekalongan.ac.id
}

\begin{abstract}
This research analyzes where the Fatwa of the Indonesian Ulama Council (MUI) Number 8 of 2011 concerning Amil Zakat is implemented. The focus of the research is on increasing or not operating costs from the Regional Budget and Expenditure (APBD) assistance for amil provided by local governments after the issuance of the fatwa. This discusses increasing the efficiency of collecting and distributing zakat funds. The samples used were the National Zakat Amil Agency (BAZNAS) Banjarnegara Regency, Kebumen, and Purbalingga with a series of times from 2011 to 2015 using saturated samples, using all samples as samples. Showing, the three District BAZNAS that have been sampled have implemented the MUI Fatwa Number 8 of 2011 concerning Amil Zakat with the amount of APBD assistance for operational costs which increased sharply after the MUI fatwa. This was also followed by the amount collected and the distribution of large zakat funds efficiently. The suggestion for the next researcher is to be able to discuss operational costs towards efficiency and distribution of zakat with regression analysis so that the results obtained become more valid and reliable, by adding samples not only to three regencies and adding a series of time not only five years.
\end{abstract}

Keywords: Amil Zakat, Zakat, the Indonesian Ulama Council (MUI)

\begin{abstract}
Abstrak
Penelitian ini menganalisis sejauh mana Fatwa Majelis Ulama Indonesia (MUI) Nomor 8 Tahun 2011 tentang Amil Zakat diimplementasikan. Fokus penelitian tertuju pada meningkat atau tidaknya biaya operasional dari bantuan Anngaran Pendapatan dan Belanja Daerah (APBD) untuk amil yang disediakan oleh pemerintah daerah setelah dikeluarkan fatwa tersebut. Hal tersebut dikaitkan dengan peningkatan efisiensi pengumpulan dan penyaluran dana zakat. Sampel yang digunakan yaitu Badan Amil Zakat Nasional (BAZNAS) Kabupaten Banjarnegara, Kebumen, dan Purbalingga dengan time series 2011 sampai 2015 menggunakan sampel jenuh yaitu menggunakan semua populasi sebagai sampel. Hasilnya, ketiga BAZNAS Kabupaten yang menjadi sampel sudah mengimplementasikan Fatwa MUI Nomor 8 Tahun 2011 tentang Amil Zakat dengan jumlah bantuan APBD untuk biaya operasional yang meningkat tajam pasca fatwa MUI tersebut. Hal itu juga diikuti dengan jumlah pengumpulan dan penyaluran dana zakat yang besar secara efisien. Saran bagi peneliti selanjutnya yaitu agar menguji pengaruh biaya operasional terhadap efisiensi pengumpulan dan penyaluran zakat dengan analisis regresi sehingga hasil yang diperoleh menjadi lebih valid dan reliabel, dengan menambah sampel tidak hanya tiga Kabupaten saja serta memperpanjang time series tidak hanya lima tahun saja.
\end{abstract}

Received: 2021-01-27 Accepted: 2021-06-22 Published: 2021-06-30

Kata kunci: Amil Zakat, Efisiensi, Fatwa, Majelis Ulama Indonesia 


\section{Pendahuluan}

Allah SWT berfirman:

"Ambillah zakat dari sebagian harta mereka, dengan zakat itu kamu membersihkan dan menyucikan mereka dan mendoalah untuk mereka. Sesungguhnya doa kamu itu (menjadi) ketenteraman jiwa bagi mereka. Dan Allah Maha Mendengar lagi Maha Mengetahui." (QS. At-Taubah: 103)

Berdasarkan ayat tersebut, dijelaskan bahwa zakat itu diambil (dijemput) dari orangorang yang berkewajiban untuk berzakat (muzakki) untuk kemudian diberikan kepada mereka yang berhak menerimanya (mustahiq). Imam al-Qurthubi ketika menafsirkan ayat tersebut, menjelaskan bahwa yang mengambil dan menjemput adalah para petugas zakat (amilin), yaitu orang-orang yang ditugaskan pemerintah untuk mengambil, menuliskan, menghitung, dan mencatat zakat yang diambilnya dari muzakki untuk kemudian diberikan kepada mustahiq. ${ }^{1}$

Rasulullah SAW pernah mempekerjakan seorang pemuda dari Suku Asad, yang bernama Ibnu Lutaibah, untuk mengurus urusan zakat Bani Sulaim. Pernah pula mengutus Ali bin Abi Thalib RA maupun Muadz bin Jabal ke Yaman untuk menjadi amil zakat. Demikian pula yang dilakukan oleh para khulafaur-rasyidin sesudahnya, mereka selalu mempunyai petugas khusus yang mengatur masalah zakat, baik pengambilan maupun distribusinya. Hal tersebut menunjukkan bahwa kewajiban zakat bukan semata-mata bersifat amal karitatif (kedermawanan), tetapi juga suatu kewajiban yang bersifat otoritatif (ijbari). Oleh karena itu, sejak zaman Rasulullah SAW sampai sekarang, pengelolaan zakat di hampir setiap negara diatur oleh pemerintah. ${ }^{2}$

Awal sejarah pelaksanaan pengelolaan zakat di Indonesia oleh pemerintah dimulai tahun 1968. Pada seminar zakat yang diselenggarakan oleh lembaga Research dan Workshop Fakultas Ekonomi Universitas Muhammadiyah Jakarta, Presiden Soeharto pertama kali mengajak masyarakat untuk melaksanakan zakat secara konkret (Karim dan Syarief, 2009). Kemudian, Presiden Soeharto dalam pidato peringatan Isra Mi'raj di istana negara tanggal 26 Oktober 1968 menganjurkan pelaksanaan zakat secara lebih intensif untuk menunjang pembangunan negara, dan Presiden siap menjadi amil zakat nasional. Seruan tersebut ditindaklanjuti dengan keluarnya Surat

\footnotetext{
1 Didin Hafidhuddin, Zakat dalam Perekonomian Modern (Jakarta: Gema Insani, 2007), Hal. 125

2 Didin Hafidhuddin, Agar Harta Berkah dan Bertambah (Jakarta: Gema Insani, 2009), Hal. 169
} 
Perintah Presiden No. 07/PRIN/1968 tanggal 31 Oktober 1968 yang memerintahkan Alamsyah, Azwar Hamid, dan Ali Afandi untuk membantu Presiden dalam administrasi penerimaan zakat. ${ }^{3}$

Page | 19 Dalam perkembangan pelaksanaan zakat di Indonesia, tampak kecenderungan baru yang merupakan perubahan ciri dari pelaksanaan zakat tersebut. Pada tanggal 29 Mei 2002, Presiden meresmikan silaturrahmi dan rapat koordinasi nasional ke I Badan Amil Zakat Nasional (BAZNAS) dan Lembaga Amil Zakat (LAZ) seluruh Indonesia di Istana Negara. Dalam pidatonya, Presiden menekankan agar BAZ baik di tingkat Nasional maupun Daerah, ataupun LAZ untuk tidak ragu-ragu bekerja sama dengan Menteri Agama, Menteri Keuangan, Menteri Negara Koperasi dan Usaha Kecil Menengah maupun menteri terkait lainnya (Suyitno, 2005: 127). Kemudian sejak dikeluarkannya Undang-undang Nomor 38 Tahun 1999 tentang pengelolaan zakat, banyak LAZ bermunculan. Fenomena menjamurnya LAZ tersebut akan makin memperkuat sistem sosial menuju civil society. ${ }^{4}$

Banyaknya amil tersebut, sedikit mengurangi peran amil tradisional yang berbasis di pesantren, masjid, sekolah. Mereka selama ini telah secara aktif menghimpun dana zakat langsung dari masyarakat, dan menggunakannya untuk kepentingan dakwah dan keumatan tanpa adanya izin yang jelas sehingga akuntabilitasnya perlu diperhatikan. Kekhawatiran ini bisa dipahami. Akan tetapi, ada hal-hal yang sangat substansial yaitu pemahaman mengenai konsep amil zakat. ${ }^{5}$

Pemerintah Indonesia telah menerapkan standarisasi amil zakat pada tahun 2013 untuk mengantisipasi hal-hal negatif yang mungkin terjadi. Hal ini merujuk pada Undang-undang Nomor 23 Tahun 2011 yang menyebutkan bahwa pengelolaan zakat diatur dengan dua model. Pertama, wewenang dan ketentuan pengelolaan zakat diatur oleh pemerintah, namun dalam pelaksanaanya pemerintah memposisikan diri sebagai regulator dan fasilitator. Kedua, wewenang pengelolaan zakat diberikan kepada masyarakat, namun diharuskan berkoordinasi, melaporkan, dan siap dibina oleh pemerintah. Kedua model tersebut akan berjalan dengan baik apabila organisasi

\footnotetext{
${ }^{3}$ Suyitno, Anatomi Fiqh Zakat, (Yogyakarta: Pustaka Pelajar, 2005), Hal. 126

${ }^{4}$ Adiwarman Karim dan Azhar Syarief, "Fenomena Unik Dibalik Menjamurnya Lembaga Amil Zakat di Indonesia", Zakat \& Empowering: Jurnal Pemikiran dan Gagasan, Vol.1, (2009), Hal. 1-9

5 Irfan Syauqi Beik, et al, "Towards an Establishment of an Efficient and Sound Zakat System", Working Group of Zakat Core Principles (2014)
} 
pengelola zakat, baik pemerintah maupun non pemerintah, memiliki good governance. ${ }^{6}$

Secara garis besar, dalam Undang-undang Nomor 23 Tahun 2011, Organisasi Pengelola Zakat (OPZ) di Indonesia dibagi menjadi dua tipe:

a. Badan Amil Zakat (BAZ), yaitu Organisasi Pengelola Zakat yang ditetapkan oleh pemerintah yang bertugas untuk mengumpulkan, mendistribusikan dana zakat sesuai dengan ketentuan yang digariskan oleh syariah. BAZ terdiri atas Badan Amil Zakat Nasional (BAZNAS) Pusat yang berkedudukan di ibukota negara, BAZNAS Provinsi, dan BAZNAS Kabupaten/Kota.

b. Lembaga Amil Zakat (LAZ), yaitu Organisasi Pengelola Zakat yang didirikan oleh masyarakat dengan persetujuan dari pemerintah untuk mengumpulkan, mendistribusikan dana zakat sesuai dengan ketentuan yang digariskan oleh syariah. Pembentukan LAZ wajib mendapat izin Menteri atau pejabat yang ditunjuk oleh Menteri. Dengan demikian, posisi LAZ tidak setara lagi dengan BAZ.

Adapun dalam penelitian ini, fokus kepada BAZ Kabupaten. Hal ini sesuai dengan Pasal 15 Undang-undang Nomor 23 Tahun 2011, yang mensyaratkan adanya BAZNAS Kabupaten untuk melaksanakan pengelolaan zakat pada tingkat Kabupaten. Saidurrahman (2013) memperkuatnya dengan menyatakan bahwa BAZNAS harus memiliki akuntabilitas kepada pemerintah serta harus mengawasi LAZ untuk menghindari terbentuknya LAZ ilegal dan memastikan bahwa LAZ senantiasa memberikan laporan secara berkala atas pelaksanaan pengumpulan, pendistribusian, dan pendayagunaan yang telah diaudit syariah dan keuangan kepada BAZ.

Kesadaran keagamaan masyarakat memang telah mendorong peningkatan jumlah pembayar zakat, yang kemudian diikuti oleh adanya pertumbuhan lembaga amil zakat secara signifikan bahwa dalam pengelolaan zakat. Namun demikian, banyak ditemukan inovasi yang dilakukan oleh amil zakat yang seringkali belum ada rujukan formal dalam ketentuan hukum Islamnya, sehingga diperlukan adanya aturan terkait pengertian amil zakat, kriteria, serta hak dan kewajibannya. Selain itu, di tengah masyarakat muncul pertanyaan mengenai hukum yang terkait dengan amil zakat, mulai

6 Kementerian Agama Republik Indonesia, Standarisasi Amil Zakat di Indonesia, Jakarta: Direktorat Pemberdayaan Zakat, (2013), Hal. 10 
dari definisi, kriteria, serta tugas dan kewenangannya. Oleh karena itu, dipandang perlu menetapkan fatwa tentang amil zakat guna dijadikan pedoman dan dasar yang kuat bagi bagi BAZNAS Kabupaten dalam menjalankan fungsinya, yaitu Fatwa Majelis Ulama Indonesia Nomor 8 Tahun 2011 tentang Amil Zakat. Dalam fatwa tersebut, diatur secara rinci mengenai pengertian amil zakat, syarat menjadi amil zakat, tugas amil zakat, biaya operasional maupun aktivitas finansial lainnya. Berkaitan dengan aktivitas finansial yang terdiri atas pengumpulan dan penyaluran dana zakat, diperlukan indikator dalam mengukur kinerja keuangan BAZNAS Kabupaten.

Para ahli menyatakan bahwa zakat bisa mungurangi kemiskinan. Namun, dalam kenyataannya besarnya dana zakat yang dihimpun maupun disalurkan belum mampu mengurangi jumlah prosentase penduduk miskin. Misalnya Kabupaten Banjarnegara, Kebumen, dan Purbalingga yang angka prosentase penduduk miskin Kabupaten masih berada diatas rata-rata prosentase penduduk miskin di Provinsi Jawa Tengah. Hal ini dibuktikan dengan data dari Badan Pusat Statistik (BPS) sebagai berikut:

Tabel 1. Prosentase Penduduk Miskin Kabupaten Banjarnegara, Kebumen, dan Purbalingga Tahun 2011-2015

\begin{tabular}{lllll}
\hline Tahun & $\begin{array}{l}\text { Rata-rata Penduduk Miskin } \\
\text { Provinsi Jawa Tengah (\%) }\end{array}$ & $\begin{array}{l}\text { Banjarnegara } \\
(\%)\end{array}$ & $\begin{array}{l}\text { Kebumen } \\
(\%)\end{array}$ & $\begin{array}{l}\text { Purbalingga } \\
(\%)\end{array}$ \\
\hline 2011 & 16,21 & 20,38 & 24,06 & 23,06 \\
2012 & 14,98 & 18,87 & 22,40 & 21,19 \\
2013 & 14,98 & 18,87 & 22,40 & 21,19 \\
2014 & 13,58 & 17,77 & 20,50 & 19,75 \\
2015 & 13,58 & 18,37 & 20,44 & 19,70 \\
\hline
\end{tabular}

Sumber: Data dan Informasi Kemisikinan Kabupaten/Kota, Badan Pusat Statistik

Pengukuran kinerja dalam suatu organisasi dibutuhkan untuk menjamin operasional perusahaan dalam mencapai tujuannya. ${ }^{7}$ Salah satu indikator yang harus diukur adalah efisiensi, karena efisiensi menunjukkan output maksimal yang mampu dihasilkan berdasarkan input yang tersedia. ${ }^{8}$ Efisiensi bermanfaat untuk memantau dan

\footnotetext{
${ }^{7}$ Noor, A.H.M., et al, What The Determine Professionalism? A Study on Zakat Institutions Integration Effort into The Mainstream Economy. Middle-East Journal of Scientific Research, Vol.27, No.2, 2014.

${ }^{8}$ Ahmad, I. dan M. Ma'in, The Efficiency of Collection and Distribution: Evidence from Two Stage Analysis, Journal of Economic Coorporation and Development, Vol. 35, No.3, Hal. 133-170, 2014.
} 
meningkatkan kinerja organisasi, termasuk didalamnya adalah Organisasi Pengelola Zakat (OPZ). Dalam OPZ, efisiensi diukur melalui bagaimana input ditransformasikan menjadi output. Salah satu tujuan evaluasi kinerja yaitu mengukur efisiensi sebagai bentuk pertanggungjawaban kepada zakat stakeholder dan kepatuhan terhadap Allah SWT. ${ }^{9}$

Kinerja BAZNAS Kabupaten terdiri atas dua aktivitas utama, yaitu pengumpulan dan penyaluran dana zakat. Untuk menunjang kinerja tersebut, dibutuhkan biaya operasional yang jumlahnya tidak sedikit. Dengan adanya Fatwa MUI Nomor 8 Tahun 2011, yang menyatakan bahwa biaya operasional pengelolaan zakat berasal dari ulil amri (pemerintah), maka perlu dikaji apakah fatwa tersebut benar-benar diimplementasikan atau tidak. Hal tersebut bisa dilihat dari perbedaan besarnya biaya operasional dari bantuan APBD sebelum dikeluarkan fatwa MUI tersebut maupun setelah dikeluarkan fatwa MUI tersebut. Idealnya semakin besar jumlah biaya operasional dari bantuan APBD, semakin besar pula jumlah pengumpulan dan penyaluran dana zakat. Oleh karena itu, penelitian ini penting dilakukan guna menjawab pertanyaan bagaimana implementasi fatwa MUI Nomor 8 Tahun 2011 dalam meningkatkan efisiensi pengumpulan maupun penyaluran dana zakat oleh amil zakat.

Konsep amil yang terdapat pada nash al-qur'an dan hadits, bukanlah orang perorangan secara sembarangan, melainkan orang ataupun kelompok orang yang tertata dalam satu manajemen pengelolaan yang terlembagakan dengan baik, serta memiliki legalitas hukum yang kuat. Oleh karena itu, dalam QS. At-Taubah ayat 60 disebut dengan kata amilin yang menurut para ulama tafsir, memiliki kewenangan dan kekuatan secara yuridis formal. Majelis Ulama Indonesia, sebagai wadah para ulama, kyai, dan ormas Islam di tanah air, mengeluarkan Fatwa MUI No 8 tahun 2011 tentang Amil Zakat. Dalam fatwa tersebut, dinyatakan bahwa yang dimaksud dengan amil zakat adalah seseorang atau sekelompok orang yang diangkat oleh pemerintah, ataupun yang dibentuk oleh masyarakat dan disahkan oleh pemerintah, untuk mengelola pelaksanaan ibadah zakat. Dengan adanya fatwa ini, maka tidak bisa sembarangan orang mengklaim dirinya sebagai amil,

\footnotetext{
${ }^{9}$ Noor, A.H.M., et al, Efficiency of Islamic Institutions: Empirical Evidence Zakat Organizations Performances in Malaysia, Journal of Economics, Business, and Management, Vol.3, No.2, 2015.
} 
apalagi amil ini hanya muncul setahun sekali, yaitu di bulan Ramadhan saja sehingga ini akan mereduksi edukasi publik yang selama ini kita gencarkan, yaitu amil itu harus profesional dan bekerja penuh waktu. Tidak boleh amil itu bekerja secara asal-asalan, apalagi orientasinya hanya untuk mendapatkan uang. ${ }^{10}$

Selain berkaitan dengan aktivitas pengumpulan dana zakat, diatur pula aktivitas penyaluran dana zakat agar lembaga zakat memperhatikan efisiensinya. Kinerja yang rendah dalam mengatur penyaluran zakat akan membuat reputasi negatif bagi organisasi pengelola zakat, terutama komitmen muzakki untuk membayarkan zakatnya melalui lembaga tersebut. Dengan kata lain, muzakki akan lebih suka membayarkan zakatnya secara langsung kepada mustahiq daripada melalui organisasi pengelola zakat karena kurang percaya terhadap kredibilitas lembaga tersebut. ${ }^{11}$ Secara teori, amil zakat seharusnya menyalurkan seluruh dana zakat yang terkumpul kepada fakir dan miskin maupun golongan lain yang berhak menerimanya. Apabila masih ada dana zakat yang tersisa maka bisa dikatakan amil tersebut tidak adil. Oleh karena itu, agar dalam pengumpulan maupun penyaluran dana zakat oleh BAZNAS Kabupaten dapat dilaksanakan secara efisien, maka peran serta pemerintah daerah sangat dibutuhkan yaitu dengan memberikan bantuan dana APBD seperti telah diatur dengan jelas dalam Fatwa MUI Nomor 8 Tahun 2011 tersebut.

Dalam hal operasional pengumpulan dan penyaluran zakat dimungkinkan adanya inovasi dan pengembangan tata cara seiring dengan dinamika sosial masyarakat sepanjang sesuai dengan ketentuan. Selain itu, tengah masyarakat muncul pertanyaan mengenai ketentuan penggumpulan dan penyaluran harta zakat serta sumber biaya operasional untuk kepentingan pengumpulan dan penyaluran zakat. Oleh karena itu, MUI juga telah mengeluarkan fatwa tentang penarikan, pemeliharaan, dan penyaluran harta zakat yaitu Fatwa MUI Nomor 15 Tahun 2011. Dalam fatwa ini dijelaskan bahwa kegiatan pengumpulan harta zakat yang meliputi pendataan wajib zakat, penentuan objek wajib zakat, besaran nishab zakat, besaran tarif zakat, dan syarat-syarat tertentu pada masing-masing objek wajib zakat. Sedangkan penyaluran

\footnotetext{
${ }^{10}$ Irfan Syauqi Beik, et al, "Towards an Establishment of an Efficient and Sound Zakat System", Working Group of Zakat Core Principles (2014)

${ }^{11}$ Mustaffha, N., Zakat Disbursement Efficiency: A Comparative Study of Zakat Institutions in Malaysia, Malaysia: International Islamic University Malaysia, 2007.
} 
zakat adalah kegiatan pendistribusian harta zakat agar sampai kepada para mustahiq zakat secara benar dan baik.

Efisiensi merupakan istilah untuk mengukur bagaimana organisasi memanfaatkan sumber daya dalam mencapai tujuannya. ${ }^{12}$ Efisiensi berarti meminimumkan input agar dapat memperoleh output yang maksimal. ${ }^{13}$ Dalam mengukur efisiensi institusi zakat harus berkaitan erat dengan pelaksanaan kewajiban dan tanggung jawab mereka untuk melindungi perekonomian dan mewujudkan keadilan sosial bagi masyarakat muslim. ${ }^{14}$ Oleh karena itu, indikator efisiensi dibutuhkan untuk memastikan operasional institusi zakat berada dalam level yang optimum. Indikator tersebut seharusnya menjangkau area-area strategis seperti penyaluran zakat, waktu penyaluran, alokasi dana yang efektif, rasio biaya operasional terhadap penyaluran, kualitas tata kelola, dan kualitas program penyaluran. ${ }^{15}$

Manajemen zakat terdiri atas dua aktivitas utama yaitu pengumpulan dan penyaluran. ${ }^{16}$ Dalam penyaluran zakat harus lebih berhati-hati karena distribusinya diatur dengan jelas dalam Al-Qur'an. ${ }^{17} \mathrm{Hal}$ ini menjadi perhatian penting bagi amil zakat yang melaksanakan amanat tersebut seperti tertera dalam Undang-undang tentang Pengelolaan Zakat No.23 tahun $2011 .{ }^{18}$ Oleh karena itu, manajemen pengelolaan zakat harus menegakkan prinsip akuntabilitas, transparansi, dan profesionalisme. Termasuk juga didalamnya perlu adanya efisiensi dan efektivitas. ${ }^{19}$

\footnotetext{
${ }^{12}$ Farrell, M.J., The Measurement of Productive Efficiency, Journal of Royal Statistical Society, Vol.120, No.3, Hal.253-290, 1957.

${ }^{13}$ Rahman, A.R.A., Pre-Requisites for Effective Integration of Zakat into Maistream Islamic Financial System in Malaysia, Islamic Economis Studies, Vol.14, No.2, 2007.

14 Noor, A.H.M., et al, Efficiency of Islamic Institutions: Empirical Evidence Zakat Organizations Performances in Malaysia, Journal of Economics, Business, and Management, Vol.3, No.2, 2015.

${ }^{15}$ Nurul Nabilah Haji Ali, "The Influence of Governance to Zakat Disbursement Efficiency: Empirical Evidence from Brunei Darussalam" Tesis, (International Islamic University Malaysia, Malaysia, 2015)

${ }^{16}$ Ahmad F. Oran, "Zakat Funds and Wealth Creation" Review of Islamic Economics, Vol.13, No.1 (2009) :143-154

${ }_{17}$ Mustaffha, N., Zakat Disbursement Efficiency: A Comparative Study of Zakat Institutions in Malaysia, Malaysia: International Islamic University Malaysia, 2007.

18 Aan Slamet Rusydiana dan Salman Al-Farisi. "The Efficiency of Zakah Institutions Using Data Envelopment Analysis" AL-IQTISHAD Jurnal of Islamic Economics, Vol.8, No.2, (2016), 213-226

19 Irfan Syauqi Beik, et al, "Towards an Establishment of an Efficient and Sound Zakat System", Working Group of Zakat Core Principles (2014)
} 
Dalam mengukur efisiensi dan efektivitas manajemen zakat, BAZNAS dan Bank Indonesia menginisiasi konsep Zakat Core Principles (ZCP) yang dapat menjadi pedoman pengelolaan zakat bukan hanya di Indonesia saja melainkan di dunia Internasional. Dalam hal ini, Indonesia mempunyai karakteristik unik dalam pengelolaan zakat. Dalam ZCP, Indonesia termasuk kedalam negara yang menganut prinsip sukarela dalam pengumpulan dana zakat. Serta dapat dilakukan oleh lembaga pemerintah maupun non-pemerintah. Tidak seperti negara-negara di timur tengah yaitu Arab Saudi, Sudan, Libya, Yaman, Kuwait, dan Pakistan, yang diwajibkan serta dikelola sepenuhnya oleh pemerintah.

Dalam mengukur tingkat efisiensi institusi zakat salah satunya adalah menilai proporsi penyaluran zakat terhadap jumlah penerima zakat. ${ }^{20}$ Aspek yang paling penting dalam mengukur efisiensi adalah memahami variabel input dan output yang akan digunakan. ${ }^{21}$ Tingginya dana zakat yang tersalurkan ketika biaya administrasi lebih dari $18 \%$ dana zakat yang tersalurkan. ${ }^{22}$ Pemerintah Jordania, Mesir, Kuwait, dan Sudan menanggung sebagian besar biaya administrasi sehingga dana zakat yang terkumpul bisa disalurkan dengan lebih optimal. ${ }^{23}$

Pengukuran efisiensi penyaluran zakat dirumuskan dalam Zakat Core Principles (ZCP) yaitu dengan DCR (Disbursement to Collection Ratio). Rasio ini menilai kemampuan OPZ dalam mendistribusikan zakatnya dengan membagi dana zakat yang tersalurkan dengan dana zakat yang terkumpul. Penyaluran zakat yang inefisien akan mengakibatkan asnaf menjadi tidak puas.

Tanggung jawab organisasi pengelola zakat dalam menyalurkan dana zakat yang terkumpul akan memberikan banyak manfaat. Barangkali, jika OPZ menyalurkan zakat secara inefisien mengakibatkan ketidakpercayaan muzakki sehingga mereka akan menyalurkan zakatnya secara langsung tanpa melalui OPZ. Dengan demikian, pengukuran efisiensi penyaluran zakat menjadi salah satu cara untuk memperbaiki

\footnotetext{
${ }^{20}$ Rahman, A.R.A., Pre-Requisites for Effective Integration of Zakat into Maistream Islamic Financial System in Malaysia, Islamic Economis Studies, Vol.14, No.2, 2007.

${ }^{21}$ Wahab, N.A dan A.R.A Rahman. A Framework to Analyse Efficiency and Governance of Zakat Institutions. Journal of Islamic Accounting and Business Research, Vol.2, No.1, 2011.

${ }^{22}$ Salama, A.A., Fiscal Analysis of Zakat with Special Reference to Saudi Arabia Experience. ICREI, 2000.

${ }^{23}$ Kahf, M., Al Waqf al Islami, Tatawwuruh, Idratuh, Tanmiyatuh (Islamic Waqf, Its Growth, Management, and Development), Damascus: Dar Al Fikr, 2000.
} 
kinerja organisasi pengelola zakat serta memperoleh kembali kepercayaan masyarakat terhadap kredibilitas lembaga tersebut. Hal ini menjadi penting dan krusial supaya masyarakat mau menyalurkan zakatnya melalui organisasi pengelola zakat. ${ }^{24}$

\section{Metode Penelitian}

Metode pemilihan sampel dalam penelitian ini menggunakan teknik sampel jenuh. Penggunaan metode ini dilakukan dengan dengan mengambil seluruh populasi sebagai sampel. Penelitian ini menggunakan data panel yaitu pada BAZNAS Kabupaten Banjarnegara, Kebumen, dan Purbalingga dari tahun 2011 sampai 2015. Sumber penelitian adalah data primer. Data primer yang dibutuhkan dalam penelitian ini berupa laporan keuangan yang terkait masalah penelitian.

Teknik pengumpulan data dilakukan dengan metode dokumentasi. Dokumentasi yaitu cara pengumpulan data dengan mengkaji dan menganalisis neraca, laporan penggunaan dana, laporan arus kas, laporan aset kelolaan, dan laporan lainnya yang terdokumentasi dalam laporan keuangan maupun dokumen lainnya.

Analisis data yang akan dilakukan terdiri atas dekripsi dan analisis isi. Deskripsi peneliti akan memaparkan data-data atau hasil penelitian melalui teknik pengumpulan data. Data yang terkumpul kemudian akan dianalisis dengan analisis kualitatif. Dalam hal ini analisis isi akan menjelaskan mengenai bagaimana Fatwa MUI Nomor 8 Tahun 2011 Tentang Amil Zakat dapat meningkatkan efisiensi pengumpulan dan penyaluran dana zakat di BAZNAS masing-masing Kabupaten yang diteliti. Berikut adalah definisi operasional variabel dan pengukurannya:

\footnotetext{
${ }^{24}$ Nasim Shah Shirazi, "Providing for the Resource Shortfallfor Poverty Elimination through the Institution of Zakat in Low-Income Muslim Countries" IIUM Journal of Economics and Management, Vol.14, No.1, (2006) : 1-21
} 
Tabel 2. Definisi Operasional Variabel dan Pengukurannya

\begin{tabular}{|c|c|c|c|}
\hline Variabel & Definisi Operasional & Pengukuran & Sumber \\
\hline $\begin{array}{l}\text { Disbursement } \\
\text { Efficiency }\end{array}$ & $\begin{array}{l}\text { Disbursement Efficiency } \\
\text { merupakan tingkat } \\
\text { efisiensi penyaluran dana } \\
\text { zakat berdasarkan } \\
\text { persentase terhadap dana } \\
\text { zakat yang terkumpul } \\
\text { sehingga bisa diketahui } \\
\text { apakah dana zakat yang } \\
\text { terkumpul dapat } \\
\text { tersalurkan semua atau } \\
\text { tidak }\end{array}$ & $\frac{\text { Total Dana Zakat Tersalurkan }}{\text { Total Dana Zakat Terkumpul }}$ & $\begin{array}{l}\text { Mustaffha } \\
\text { (2007) }\end{array}$ \\
\hline
\end{tabular}

\section{Hasil dan Pembahasan}

Data-data dokumentasi yang diperoleh peneliti yaitu jumlah dana terhimpun, jumlah dana tersalurkan, serta jumlah bantuan dana APBD, dari BAZNAS Banjarnegara, Kebumen, dan Purbalingga selama 5 tahun dari tahun 2011 sampai 2015 berikut:

Tabel 3. Aktivitas Pengelolaan Zakat Pada Badan Amil Zakat Nasional Kabupaten Banjarnegara Tahun 2011-2015

\begin{tabular}{|c|c|c|c|c|c|c|}
\hline \multirow{2}{*}{ Tahun } & \multicolumn{2}{|c|}{ Bantuan APBD } & \multicolumn{2}{|l|}{ Dana Terhimpun } & \multicolumn{2}{|l|}{ Dana Tersalurkan } \\
\hline & $\mathbf{R p}$ & $\%$ & $\mathbf{R p}$ & $\%$ & $\mathbf{R p}$ & $\%$ \\
\hline 2011 & $16.700 .000,00$ & & $343.549 .796,00$ & & $257.662 .347,00$ & \\
\hline 2012 & $32.000 .000,00$ & 192 & $821.640 .286,00$ & 239 & $616.230 .215,00$ & 239 \\
\hline 2013 & $32.000 .000,00$ & 100 & $1.498 .217 .753,00$ & 182 & $1.123 .663 .315,00$ & 182 \\
\hline 2014 & $41.500 .000,00$ & 130 & 1.929.137.112,00 & 129 & $1.446 .852 .834,00$ & 129 \\
\hline 2015 & $70.000 .000,00$ & 169 & $2.228 .372 .908,00$ & 116 & $1.671 .279 .681,00$ & 116 \\
\hline
\end{tabular}

Sumber: Laporan Keuangan Tahunan BAZNAS Kabupaten Banjarnegara

BAZNAS Kabupaten Banjarnegara pada tahun 2011 (sebelum dikeluarkannya fatwa MUI nomor 8 tahun 2011), mendapat bantuan APBD untuk biaya operasional sebesar Rp 16.700.000,00. Jumlah tersebut naik drastis sebesar 192\% menjadi Rp 32.000.000,00 pada tahun 2012 (setelah dikeluarkannya fatwa MUI nomor 8 tahun 
2011). Hal tersebut menunjukkan bahwa fatwa MUI nomor 8 tahun tentang amil zakat berperan penting dalam kenaikan bantuan APBD tersebut karena dalam fatwa tersebut jelas diatur bahwa biaya pengelolaan oleh disediakan oleh pemerintah, sehingga Pemerintah Kabupaten Banjarnegara tidak ragu lagi mengucurkan dana APBD hampir dua kali lipat dari tahun sebelumnya kepada BAZNAS Kabupaten Banjarnegara.

Dalam aktivitasnya, BAZNAS Kabupaten Banjarnegara juga mengalami kenaikan yang cukup signifikan pasca dikeluarkannya fatwa MUI tersebut, baik dari segi pengumpulan maupun penyaluran zakat. Pada tahun 2011 (sebelum dikeluarkannya fatwa MUI nomor 8 tahun 2011), mendapat berhasil mengumpulkan dana zakat sebesar Rp 343.549.796,00 dan menyalurkannya sebesar Rp 257.662.347,00. Pada tahun 2012 (setelah dikeluarkannya fatwa MUI nomor 8 tahun 2011) jumlah tersebut naik sebesar 239\%, baik pengumpulan maupun penyaluran, yaitu sebesar Rp 821.640.286,00 untuk pengumpulan zakat dan disalurkan sebesar Rp 616.230.215,00. Hal tersebut menunjukkan bahwa kenaikan biaya operasional dari bantuan APBD menyebabkan naiknya jumlah pengumpulan maupun penyaluran dana zakat, pasca dikeluarkannya fatwa MUI nomor 8 tahun tentang amil zakat.

Berkaitan dengan efisiensi, mengacu pada DCR (Disbursement to Collection Ratio) dengan rumus jumlah dana zakat dibagi dengan jumlah dana zakat yang disalurkan, diperoleh hasil yaitu sebesar 75\% untuk tahun 2011 maupun tahun 2012 dengan kriteria efisien. Dengan demikian, meskipun presentase rasio DCR tetap sebesar $75 \%$, namun kriterianya masih efisien, sehingga implementasi fatwa MUI nomor 8 tentang amil zakat dapat meningkatkan efisiensi pengumpulan maupun penyaluran dana zakat.

Tabel 4. Aktivitas Pengelolaan Zakat Pada Badan Amil Zakat Nasional Kabupaten Kebumen Tahun 2011-2015

\begin{tabular}{|c|c|c|c|c|c|c|}
\hline \multirow{2}{*}{ Tahun } & \multicolumn{2}{|l|}{ Bantuan APBD } & \multicolumn{2}{|l|}{ Dana Terhimpun } & \multicolumn{2}{|l|}{ Dana Tersalurkan } \\
\hline & $\mathbf{R p}$ & $\%$ & $\mathbf{R p}$ & $\%$ & $\mathbf{R p}$ & $\%$ \\
\hline 2011 & $10.000 .000,00$ & & $913.658 .073,00$ & & $769.541 .985,00$ & \\
\hline 2012 & $90.000 .000,00$ & 900 & $1.640 .578 .526,00$ & 180 & $1.214 .696 .088,00$ & 158 \\
\hline 2013 & $115.000 .000,00$ & 128 & $2.357 .361 .410,00$ & 144 & $1.519 .714 .837,00$ & 125 \\
\hline
\end{tabular}


Efisiensi Pengelolaan Zakat...

\begin{tabular}{llccccc}
\hline 2014 & $100.000 .000,00$ & 87 & $3.080 .921 .058,00$ & & $1.995 .542 .080,00$ & 131 \\
& & 100 & & 84 & & 119 \\
2015 & $100.000 .000,00$ & & $2.597 .703 .081,00$ & & $2.367 .042 .239,00$ & \\
\hline
\end{tabular}

Page 29 Sumber: Laporan Keuangan Tahunan BAZNAS Kabupaten Kebumen

BAZNAS Kabupaten Kebumen pada tahun 2011 (sebelum dikeluarkannya fatwa MUI nomor 8 tahun 2011), mendapat bantuan APBD untuk biaya operasional sebesar Rp 10.000.000,00. Jumlah tersebut naik drastis sebesar 900\% menjadi Rp 90.000.000,00 pada tahun 2012 (setelah dikeluarkannya fatwa MUI nomor 8 tahun 2011). Hal tersebut menunjukkan bahwa fatwa MUI nomor 8 tahun tentang amil zakat berperan penting dalam kenaikan bantuan APBD tersebut karena dalam fatwa tersebut jelas diatur bahwa biaya pengelolaan oleh disediakan oleh pemerintah, sehingga Pemerintah Kabupaten Kebumen tidak ragu lagi mengucurkan dana APBD sembilan kali lipat dari tahun sebelumnya kepada BAZNAS Kabupaten Kebumen.

Dalam aktivitasnya, BAZNAS Kabupaten Kebumen juga mengalami kenaikan yang cukup signifikan pasca dikeluarkannya fatwa MUI tersebut, baik dari segi pengumpulan maupun penyaluran zakat. Pada tahun 2011 (sebelum dikeluarkannya fatwa MUI nomor 8 tahun 2011), mendapat berhasil mengumpulkan dana zakat sebesar Rp 913.658.073,00 dan menyalurkannya sebesar Rp 769.541.985,00. Pada tahun 2012 (setelah dikeluarkannya fatwa MUI nomor 8 tahun 2011) jumlah tersebut naik sebesar 180\% untuk pengumpulan dan 158\% untk penyaluran, yaitu sebesar Rp 1.640.578.526,00 untuk pengumpulan zakat dan disalurkan sebesar $\mathrm{Rp}$ 1.214.696.088,00. Hal tersebut menunjukkan bahwa kenaikan biaya operasional dari bantuan APBD menyebabkan naiknya jumlah pengumpulan maupun penyaluran dana zakat, pasca dikeluarkannya fatwa MUI nomor 8 tahun tentang amil zakat.

Berkaitan dengan efisiensi, mengacu pada DCR (Disbursement to Collection Ratio) dengan rumus jumlah dana zakat dibagi dengan jumlah dana zakat yang disalurkan, diperoleh hasil yaitu sebesar 84\% untuk tahun 2011 dan 74\% untuk tahun tahun 2012 dengan kriteria efisien. Dengan kriteria yang efisien, dapat dikatakan bahwa implementasi fatwa MUI nomor 8 tentang amil zakat dapat meningkatkan efisiensi pengumpulan maupun penyaluran dana zakat. 
Tabel 5. Aktivitas Pengelolaan Zakat Pada Badan Amil Zakat Nasional Kabupaten Purbalingga Tahun 2011-2015

\begin{tabular}{|c|c|c|c|c|c|c|}
\hline \multirow{2}{*}{ Tahun } & \multicolumn{2}{|c|}{ Bantuan APBD } & \multicolumn{2}{|l|}{ Dana Terhimpun } & \multicolumn{2}{|l|}{ Dana Tersalurkan } \\
\hline & Rp & $\%$ & $\mathbf{R p}$ & $\%$ & $\operatorname{Rp}$ & $\%$ \\
\hline 2011 & $36.000 .000,00$ & & $936.588 .990,00$ & & $701.693 .021,00$ & \\
\hline & & 139 & & 117 & & 141 \\
\hline 2012 & $50.000 .000,00$ & & $1.094 .248 .426,00$ & & $987.957 .229,00$ & \\
\hline & & 100 & & 105 & & 91 \\
\hline 2013 & $50.000 .000,00$ & & $1.152 .495 .503,00$ & & $902.180 .046,00$ & \\
\hline 2014 & $50.000 .000,00$ & 100 & $1.522 .431 .566,00$ & 132 & $1.234 .700 .304,00$ & 137 \\
\hline 2015 & $50.000 .000,00$ & 100 & $1.972 .786 .327,00$ & 130 & $1.890 .756 .582,00$ & 153 \\
\hline
\end{tabular}

Sumber: Laporan Keuangan Tahunan BAZNAS Kabupaten Purbalingga

BAZNAS Kabupaten Purbalingga pada tahun 2011 (sebelum dikeluarkannya fatwa MUI nomor 8 tahun 2011), mendapat bantuan APBD untuk biaya operasional sebesar Rp 36.000.000,00. Jumlah tersebut naik drastis sebesar 139\% menjadi Rp 50.000.000,00 pada tahun 2012 (setelah dikeluarkannya fatwa MUI nomor 8 tahun 2011). Hal tersebut menunjukkan bahwa fatwa MUI nomor 8 tahun tentang amil zakat berperan penting dalam kenaikan bantuan APBD tersebut karena dalam fatwa tersebut jelas diatur bahwa biaya pengelolaan oleh disediakan oleh pemerintah, sehingga Pemerintah Kabupaten Purbalingga tidak ragu lagi mengucurkan dana APBD lebih besar dari tahun sebelumnya kepada BAZNAS Kabupaten Purbalingga.

Dalam aktivitasnya, BAZNAS Kabupaten Purbalingga juga mengalami kenaikan yang cukup signifikan pasca dikeluarkannya fatwa MUI tersebut, baik dari segi pengumpulan maupun penyaluran zakat. Pada tahun 2011 (sebelum dikeluarkannya fatwa MUI nomor 8 tahun 2011), mendapat berhasil mengumpulkan dana zakat sebesar Rp 936.588.990,00 dan menyalurkannya sebesar Rp 701.693.021,00. Pada tahun 2012 (setelah dikeluarkannya fatwa MUI nomor 8 tahun 2011) jumlah tersebut naik sebesar $117 \%$ untuk pengumpulan dan $141 \%$ penyaluran, yaitu sebesar Rp 1.094.248.426,00 untuk pengumpulan zakat dan disalurkan sebesar Rp 987.957.229,00. Hal tersebut menunjukkan bahwa kenaikan biaya operasional dari bantuan APBD menyebabkan naiknya jumlah pengumpulan maupun penyaluran dana zakat, pasca dikeluarkannya fatwa MUI nomor 8 tahun tentang amil zakat. 
Berkaitan dengan efisiensi, mengacu pada DCR (Disbursement to Collection Ratio) dengan rumus jumlah dana zakat dibagi dengan jumlah dana zakat yang disalurkan, diperoleh hasil yaitu sebesar 84\% untuk tahun 2011 dan 74\% untuk tahun tahun 2012 dengan kriteria efisien. Dengan kriteria yang efisien, dapat dikatakan bahwa implementasi fatwa MUI nomor 8 tentang amil zakat dapat meningkatkan efisiensi pengumpulan maupun penyaluran dana zakat. Dari pembahasan pada ketiga BAZNAS Kabupaten diatas, dapat diketahui bahwa ketiga BAZNAS tersebut mengalami kenaikan bantuan APBD untuk biaya operasional yang cukup signifikan. Kenaikan tersebut terjadi pada tahun 2012, yaitu pasca dikeluarkannya Fatwa MUI Nomor 8 Tahun 2011 tentang Amil Zakat. Hal tersebut mempengaruhi besarnya dana zakat terkumpul dan tersalurkan sehingga kinerja BAZNAS menjadi lebih efisien.

Tabel 6. Rasio Penyaluran Zakat Terhadap Pengumpulan Zakat

\begin{tabular}{lllllll}
\hline \multirow{2}{*}{ Tahun } & \multicolumn{2}{c}{ Banjarnegara } & \multicolumn{2}{l}{ Kebumen } & \multicolumn{2}{l}{ Purbalingga } \\
\cline { 2 - 7 }$\%$ & Ket. & $\%$ & Ket. & $\%$ & Ket. \\
\hline 2011 & 75 & Efficien & 84 & Efficien & 75 & Efficien \\
\hline 2012 & 75 & Efficien & 74 & Efficien & 90 & $\begin{array}{l}\text { Highly } \\
\text { efficien }\end{array}$ \\
\hline 2013 & 75 & Efficien & 64 & $\begin{array}{l}\text { Fairly } \\
\text { efficien }\end{array}$ & 78 & Efficien \\
\hline 2014 & 75 & Efficien & 65 & $\begin{array}{l}\text { Fairly } \\
\text { efficien }\end{array}$ & 81 & Efficien \\
\hline 2015 & 75 & Efficien & 91 & $\begin{array}{l}\text { Highly } \\
\text { efficien }\end{array}$ & 96 & $\begin{array}{l}\text { Highly } \\
\text { efficien }\end{array}$ \\
\hline $\begin{array}{l}\text { Rata- } \\
\text { rata }\end{array}$ & 75 & Efficien & 76 & Efficien & 84 & Efficien \\
\hline
\end{tabular}

Berdasarkan data tersebut, ketiga BAZNAS Kabupaten yang menjadi objek penelitian semuanya mengalami kenaikan bantuan APBD, dana terhimpun, maupun dana tersalurkan sejak tahun 2011 sampai 2015. Fokus penelitian ini tertuju pada tahun 2011 dan 2012 karena disitulah cut-off dikeluarkannya fatwa MUI nomor 8 tahun 2011 tentang amil zakat. 


\section{Simpulan}

Dalam zakat, amil memang termasuk salah satu asnaf yang berhak menerima zakat sehingga mereka mendapatkan porsi tersendiri sebesar $12,5 \%$. Namun, OPZ sebaiknya berusaha meminimalisasi biaya administrasi agar tidak terlampau besar sehingga dana zakat bisa lebih bermanfaat dan terbagikan kepada tujuh asnaf yang lain.

Fatwa MUI Nomor 8 Tahun 2011 menyatakan agar BAZNAS Kabupaten tidak terlalu bergantung pada dana bantuan APBD sebagai biaya operasional. BAZNAS Kabupaten juga bisa menggunakan dana infaq, shodaqoh, maupun bagi hasil bank syariah sebagai biaya operasional. Namun, nominal yang kecil dan tidak menentu atas dana-dana tersebut menjadikan bantuan APBD menjadi penting dan dibutuhkan oleh BAZNAS Kabupaten guna menunjang biaya operasional dalam upaya menyalurkan dana zakat kepada mustahiq.

Kesimpulan dari penelitian ini adalah Fatwa MUI Nomor 8 Tahun 2011 telah diimplementasikan dengan baik oleh BAZNAS Kabupaten yang menjadi sampel penelitian. Pemerintah Daerah telah melaksanakan fatwa MUI tersebut dengan memberikan bantuan APBD sebagai biaya operasional BAZNAS jauh lebih besar dari tahun-tahun sebelumnya, yaitu mulai tahun 2012 (pasca dikeluarkannya Fatwa MUI Nomor 8 Tahun 2011 tentang Amil Zakat). Hal tersebut terbukti dapat meningkatkan efisiensi pengumpulan maupun penyaluran zakat pada BAZNAS Kabupaten Banjarnegara, Kebumen, dan Purbalingga.

Fakta diatas menunjukkan besarnya peran Fatwa MUI di bidang syariah dalam kehidupan berbangsa dan bernegara. Dengan semakin efisiennya BAZNAS Kabupaten dalam menjalaskan tugasnya, tentu akuntabilitas akan tetap terjaga. Stakeholder utama yaitu muzakki dan mustahiq menjadi lebih puas terhadap kinerja BAZNAS Kabupaten. Bagi muzakki, akan lebih percaya menyalurkan zakatnya melalui BAZNAS dan tidak lagi menyalurkan zakatnya secara langsung kepada mustahiq. Sedangkan bagi mustahiq, mereka semakin yakin terhadap hakhaknya yang dijaga dengan baik oleh BAZNAS. Semua itu berkat Rahmat Allah SWT yang diberikan kepada Majelis Ulama Indonesia sehingga dapat membuat fatwa yang mudah diaplikasikan dalam kehidupan sehari-hari serta kemanfaatannya dirasakan secara nyata oleh masyarakat.

Saran yang dapat diberikan bagi komisi fatwa MUI adalah agar terus mengeluarkan fatwa terkait amil zakat terutama berkaitan dengan pengelolaan keuangan dan 
pengembangannya agar dana zakat bisa didayagunakan menjadi lebih bermanfaat. Saran untuk pemerintah daerah yaitu agar lebih memperbesar lagi nominal jumlah bantuan APBD untuk biaya operasional BAZNAS Kabupaten karena hal tersebut akan memperbesar pula jumlah dana zakat yang dikumpulkan maupun disalurkan secara efisien. Sedangkan bagi peneliti selanjutnya yaitu agar menguji pengaruh fatwa MUI terhadap efisiensi pengumpulan dan penyaluran zakat dengan analisis regresi sehingga hasil yang diperoleh menjadi lebih valid dan reliabel, dengan menambah sampel tidak hanya tiga Kabupaten saja serta memperpanjang time series tidak hanya lima tahun saja.

\section{DAFTAR PUSTAKA}

Ahmad, I. dan M. Ma'in, The Efficiency of Collection and Distribution: Evidence from Two Stage Analysis, Journal of Economic Coorporation and Development, Vol. 35, No.3, Hal. 133-170, 2014.

Ali, N.N.H., The Influence of Governance to Zakat Disbursement Efficiency: Empirical Evidence from Brunei Darussalam, Malaysia: International Islamic University Malaysia, 2015.

Beik, I.S., et al, Towards an Establishment of an Efficient and Sound Zakat System, Working Group of Zakat Core Principles, 2014.

Farrell, M.J., The Measurement of Productive Efficiency, Journal of Royal Statistical Society, Vol.120, No.3, Hal.253-290, 1957.

Hafidhuddin, D, Zakat dalam Perekonomian Modern, Jakarta: Gema Insani, 2007. Agar Harta Berkah dan Bertambah, Jakarta: Gema Insani, 2009.

Hatoli, Hatoli. 2020. "SERTIFIKASI HALAL MAJELIS ULAMA INDONESIA PADA PRODUK ELEKTRONIK DAN NON KONSUMSI PERSPEKTIF MASLAHAH". JIL: Journal of Islamic Law 1 (2), 237-55. https://doi.org/10.24260/jil.v1i2.45.

Haque M., et al, Measurement Optimalization of Zakat Disbribution at Lembaga Amil Zakat Using Variable Measurement of Economy, Journal of Islamic Monetary Economics and Finance, Vol.2, No.1, 2016.

Kahf, M., Al Waqf al Islami, Tatawwuruh, Idratuh, Tanmiyatuh (Islamic Waqf, Its Growth, Management, and Development), Damascus: Dar Al Fikr, 2000.

Karim A. dan A. Syarief, Fenomena Unik Dibalik Menjamurnya Lembaga Amil Zakat di Indonesia. Zakat \& Empowering, Jurnal Pemikiran dan Gagasan, Vol.1, 2009. 
Kementerian Agama Republik Indonesia, Standarisasi Amil Zakat di Indonesia, Jakarta: Direktorat Pemberdayaan Zakat, 2013.

Mustaffha, N., Zakat Disbursement Efficiency: A Comparative Study of Zakat Institutions in Malaysia, Malaysia: International Islamic University Malaysia, 2007.

Noor, A.H.M., et al, What The Determine Professionalism? A Study on Zakat Institutions Integration Effort into The Mainstream Economy. Middle-East Journal of Scientific Research, Vol.27, No.2, 2014.

Efficiency of Islamic Institutions: Empirical Evidence Zakat Organizations Performances in Malaysia, Journal of Economics, Business, and Management, Vol.3, No.2, 2015.

Oran, A.F., Zakat Funds and Wealth Creation, Review of Islamic Economics, Vol.13, No.1, 2009.

Rahman, A.R.A., Pre-Requisites for Effective Integration of Zakat into Maistream Islamic Financial System in Malaysia, Islamic Economis Studies, Vol.14, No.2, 2007.

Rusydiana, A.S dan S. Al-Farisi, The Efficiency of Zakah Institutions Using Data Envelopment Analysis, AL-IQTISHAD Jurnal of Islamic Economics, Vol.8, No.2, 2016.

Saidurrahman, The Politics of Zakat Management in Indonesia: The Tension Between BAZ and $L A Z$, Journal of Indonesian Islam, Vol.2, No.2, Hal.366-382, 2013.

Salama, A.A., Fiscal Analysis of Zakat with Special Reference to Saudi Arabia Experience. ICREI, 2000.

Shirazi, N. S., Providing for the Resource Shortfallfor Poverty Elimination through the Institution of Zakat in Low-Income Muslim Countries. IIUM Journal of Economics and Management, Vol.14, No.1, 2006.

Suyitno, Anatomi Fiqh Zakat, Yogyakarta: Pustaka Pelajar, 2005. 